\title{
What Has Happened to the Atlantic Salmon?
}

\section{Alwyne Wheeler}

Because they must migrate up to the headwaters of rivers to spawn, salmon were badly affected when man developed the rivers for navigation and industry, then polluted them and, for hydroelectric schemes, sometimes blocked them. The final disaster was the Greenland fishery that started in the early 1960s. This has now been controlled, but the Atlantic salmon is unlikely to recover its former numbers. Moreover, some of the unique stocks that each river system originally had have been exterminated and others adulterated, so that the Atlantic salmon's original genetic diversity has been irretrievably destroyed. The author, who works on fishes at the British Museum, Natural History, is Chairman of IUCN's SSC Fish Group.

One of the great natural resources of the countries bordering the North Atlantic is the salmon Salmo salar, sometimes referred to as the Atlantic salmon to distinguish it from its six Pacific relatives of the genus Oncorhynchus. In historical times the salmon had a range from the Connecticut River, in the United States, northwards and across the ocean to Europe and south to Portugal. It was an important food fish for coastal and riverine communities, and many archaeological sites of prehistoric and historic periods reveal the salmon's characteristic pierced biconcave vertebrae, sometimes in great numbers. Today numbers are much reduced and its range considerably contracted even from that of a century ago.

The salmon's migratory habit materially contributed both to its abundance and its importance as a food fish, and also to its diminution. An anadromous migrant, salmon spawn in rivers usually far upstream; as young fish they migrate to the sea to spend a period, varying from one to four years, enjoying the rich feeding, and growing to sexual maturity before returning to their natal stream. Some Atlantic (but not Pacific) salmon may spawn a second or third time, with intervening migrations to the sea for a period to recoup their condition and restore their gonads.

This migratory lifestyle means that the eggs develop in the security of the redd in the river gravel, and that the young fish (parr) grow in a restricted area with reduced competition and predation. In the sea the young salmon find an abundance of food organisms, chiefly shrimp-like crustaceans and small fishes, such as sand eels, herring, sprat and, in the Arctic, capelin, and they grow rapidly. Salmon which went to sea as smolts 5-6 inches long may weigh 3-6 lbs after their first year, and 6-15 lbs at the end of their second sea year.

The disadvantage of the need to breed in fresh water is that it forces a relatively large fish to pass through many miles of river before it can reach suitable spawning beds, and during this passage it is highly vulnerable.

No one hazard can be indicted as the major cause for the decline of the salmon; rather, a combination of factors have affected it both in time and from. 
area to area. In the densely populated parts of Europe and North America a combination of man's activities caused problems for the salmon in the 1800 s one of which was the development of many rivers for navigation in their lower and middle reaches. Pound locks through which shipping could pass had to be built, as well as associated weirs which raised the water level in the river locally. The salmon is a magnificent leaper and could negotiate low weirs and even pound locks, but many were too high to be surmounted. When the salmon were forced to gather in the weir pools, waiting for an increase in the river flow before continuing upstream, they were highly vulnerable to netting, and traps were often built into the weirs to catch them. To facilitate navigation some controlling authorities also dredged the gravel shallows which had been the spawning grounds of the salmon.

Along with this canalisation of lowland rivers went the development of industry on their banks. In the 19th century many industries contributed to river pollution, either by using the water or, more commonly, by discharging toxic waste. One of the worst was coal gas manufacture, which in its early development produced much waste of extreme toxicity, most of which went into the nearest waterway.

\section{Hydroelectricity}

These were some the hazards that contributed greatly to the decline of the salmon in the industrialised parts of its range, but more recent developments have affected the species elsewhere. In many highland rivers the development of hydro-electricity altered their flow characteristics; in some cases it 'drowned out' the spawning shallows, and in others produced impassable barriers to the migration of the spawning fish. Many hydroelectric schemes, of course, have included a fish pass to enable the salmon to continue their ascent unaided, and some even incorporate traps from which the fish are removed and transported around the barrier, but few such altered rivers now contain as large stocks as were there before alteration. On other highland rivers water storage schemes have had much the same result.

Forestry operations sometimes have severe consequences for salmon. Streams flowing through woodlands are cooler, have a more even flow, and are more richly supplied with food organisms suitable for salmon and trout parr than are comparable streams in open country. Woodland felling near forest streams immediately drives young salmonids to migrate upstream into undisturbed reaches, and although the stream will still contain salmon after felling, there will be many fewer than in a forested reach. At the other end of the forestry operation pulp mills have a serious effect on fish by discharging waste into rivers, which become turbid, toxic and deoxygenated.

These problems, which far from exhaust the reasons for the salmon's decline, are all land-based, and until the 1960s they were the major threats. But early in that decade a small fishery, started by the Greenlanders, was catching salmon in the sea off the West Greenland coast, using set gill-nets worked from the shore. Between 1960 and 1964 this fishery grew from about 100 to 1500 tonnes. Significantly, the upper figure was never exceeded, and 1964 was crucial because in that year vessels from outside Greenland began to fish in the waters farther from the coast, using drift nets near the sea's surface. This fishery quickly grew, and in 1971 took 1200 tonnes. Thus the combined fishery in West Greenland, which in the 1950s had produced only a few salmon 


\section{SALMON PARR}

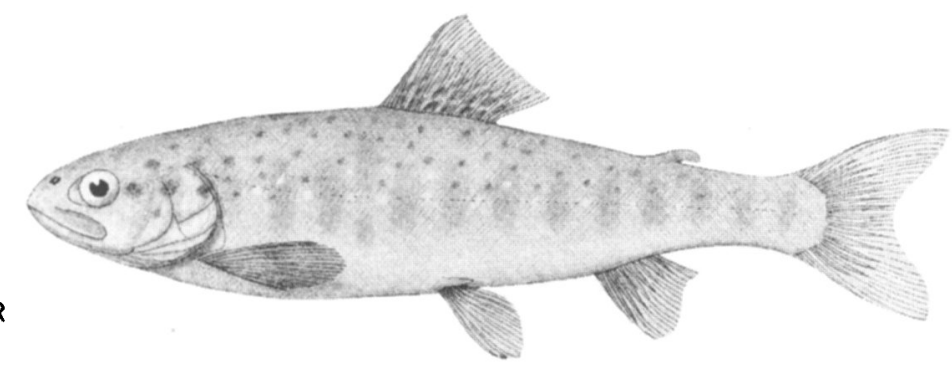

in subsistence fishing for a small human population, had grown within twenty years to produce over 2000 tonnes annually. And further high-seas fishing was carried on in the Norwegian Sea.

Not surprisingly, this heavy exploitation is thought to have tipped the balance against the salmon in the whole of the North Atlantic. Taken with all the land-based hazards that the fish faced, this additional pressure caused a further decline in numbers in home rivers. At the time that the Greenland fishery developed, fisheries scientists did not know where these high seas fish had come from, although it was certain that they were not produced by Greenland's few rivers. Research into the origin of the stock was begun, and salmon tags returned later from the fish caught off West Greenland showed that these are the feeding grounds of fish from western Europe, including the Baltic, and North America. The Norwegian Sea fish are largely of European origin.

The effects of the fishery were not immediately apparent in the statistics of the North Atlantic, because these were quantified in terms of total tonnage without reference to the 'fishing effort' involved. Thus, one year could not be compared with another because a different amount of effort had gone into making the catch from year to year. International discussions produced a rather arid conclusion that there was no clear scientific evidence that the high-seas fishery was affecting national stocks, and the specious argument that the fishery enhanced the total North Atlantic yield of salmon (a point put forward by Denmark which has no salmon rivers of its own but was a major participant in the high-seas fishery). Moreover, it takes time for a decline in an ocean's stock of fish to make itself obvious, although at a local level it becomes evident fairly quickly. Thus, the North Atlantic catch has remained fairly stable over the years from 1964, and even showed an increase in 1973 and 1974, but 1976 showed a decline (to 10,900 tonnes), the lowest catch in a dozen years. Perhaps the effects of heavy fishing have at last made themselves felt, but only later figures will establish this.

But the tagging returns show how serious the fishing pressure had become. For every two salmon from the State of Maine caught in the state's rivers, no fewer than five were caught on the high seas.

All these pressures on the salmon have reduced both its numbers and its range. Portugal's rivers now contain no salmon. In Spain commercial netting is banned but there is heavy angling pressure; with increasing industrialisation and pollution several rivers which contained salmon before the Civil War no longer do so. In France, stocks have suffered as badly as anywhere in Europe from gross overfishing by commercial fishermen and anglers, river development and pollution, and salmon rivers are now a mere handful, mostly in 
Brittany and Normandy. The Rhine is, of course, the most terrible example in Europe of a misused river: once it contained salmon from its mouth to its sources in Switzerland, but now there are none; indeed, large parts of the river have no fish at all.

Scottish rivers have the lion's share of salmon in the British Isles, although some English and Welsh rivers in the west and south-west have reasonable stocks. In eastern England the salmon is virtually extinct. In Ireland, which was until recently a salmon stronghold, there are still some, but over-fishing due to a large increase in licensed netting on the coast reduced the 1976 catch to 30 per cent less than that of 1975 , and the 1977 catch is 10 per cent lower still. The Baltic countries still have salmon - about 17 rivers in Finland, 40 in Sweden, and eight in the USSR - but there are none in the rivers discharging to the southern coastline. Both Norway and Iceland have rich salmon stocks and their rivers show few signs of the depletion elsewhere in its range. There are still many salmon rivers in Canada, where the slower pace of industrialisation and river degradation has not produced the disaster that overtook the salmon rivers of Maine and the rest of New England, in many of which the fish was exterminated. The Greenland fishery did, without doubt, reduce even these.

However, there is deep interest in the salmon, and many organisations both voluntary and official are involved in attempts to restock rivers in which the fish was once common. Pollution control has also taken a major step forward, and a number of rivers in Britain, Ireland and North America are now significantly cleaner than they were twenty years ago, raising hopes that salmon can be encouraged to re-establish themselves there. But it is a long hard struggle to re-establish a fish like the salmon - paradoxically so, compared with the speed with which they can be exterminated. It is also expensive, which may mean that it takes a lower priority than one would wish.

The phasing out of the high seas fishery off Greenland, although the coastal fishery still continues, is one positive achievement, and it has at least put an end to the situation where expensive hatchery-reared fish released into rivers were caught in the sea by someone who had no interest in the restocking attempt.

Taken overall the attempts to restock rivers have been piecemeal and usually applied to single river basins only. A few have succeeded and no doubt others will in time, but they make little significant contribution to the stock of the species. Official international cooperation in conserving the stocks is sparse, and the one successful organisation, the International Council of North-West Atlantic Fisheries (ICNAF), which achieved control of the Greenland fishery, has now largely been disbanded in favour of the EEC's fisheries policy (North American countries are spared this dubious privilege). The salmon is still an important fish, and no doubt commercial considerations will produce some fishery policies for the North Atlantic, but the stock will be reduced. At the southern edge of its range its survival is doubtful.

Originally, every major river system had a genetically unique stock; some of these have been extinguished, and many others are now adulterated by the introduction of hatchery fish from other river systems. As a result, while the Atlantic salmon is not endangered as a species, it survives with impoverished genetic diversity. 